\title{
Reduction of central line-associated bloodstream infection rates in a neonatal intensive care unit after implementation of a multidisciplinary evidence-based quality improvement collaborative: A four-year surveillance
}

\author{
Joseph Y Ting MBBS MPH MRCPCH FRCPC, Vicki SK Goh BScN, Horacio Osiovich MD FRCPC
}

JY Ting, VSK Goh, H Osiovich. Reduction of central lineassociated bloodstream infection rates in a neonatal intensive care unit after implementation of a multidisciplinary evidence-based quality improvement collaborative: A four-year surveillance. Can J Infect Dis Med Microbiol 2013;24(4):185-190.

BACKGROUND: The use of central venous catheters has permitted lifesaving treatment for critically ill neonates; however, the attributable mortality rate for central line-associated bloodstream infections (CLABSIs) has been estimated to be between $4 \%$ and 20\%. In 2006/2007, the authors' neonatal intensive care unit (NICU) had a CLABSI rate that was nearly twofold higher than that reported by other Canadian NICUs. OBJECTIVE: To implement a quality improvement collaborative to reduce the incidence of neonatal CLABSI.

METHODS: A retrospective observational study was performed to compare CLABSI in neonates admitted to the authors' level III NICU between August 2007 and March 2011. The entire study period was divided into four time periods to evaluate secular trends. A comprehensive catheter-related bloodstream infection prevention initiative was implemented in August 2007. The initiatives included staff education, standardization of skin preparation protocol, introduction of new antiseptic agents, implementation of central catheter insertion and maintenance checklists, reinforcement of the use of maximal sterile barrier precautions, and revision of the central catheter configuration and maintenance protocols.

RESULTS: The median CLABSI rate of 7.9 per 1000 catheter days at the beginning of the study (period 1 [August 2007 to June 2008]) gradually decreased over the entire study period $(\mathrm{P}=0.034)$ : period 2 (July 2008 to May 2009), 3.3 per 1000 catheter days; period 3 (June 2009 to April 2010), 2.6 per 1000 catheter days; and period 4 (May 2010 to March 2011), 2.2 per 1000 catheter days.

CONCLUSION: A multidisciplinary evidence-based quality improvement collaborative resulted in a significant reduction in the CLABSI rate. Continuous quality improvement measures are required to reduce catheter-related bloodstream infections among low-birth-weight infants.

Key Words: Bloodstream infection; Central line; Neonate
La réduction du taux d'infections sanguines associées à un cathéter central dans une unité de soins intensifs néonatals après l'adoption d'une collaboration multidisciplinaire visant l'amélioration de la qualité fondée sur des données probantes : quatre ans de surveillance

HISTORIQUE : Le recours aux cathéters veineux centraux permet de prodiguer des traitements salutaires aux nouveau-nés gravement malades. Toutefois, on évalue de $4 \%$ à $20 \%$ le taux de mortalité attribué aux infections sanguines associées à un cathéter central (ISACC). En 2006-2007, à l'unité de soins intensifs néonatals (USIN) des auteurs, le taux d'ISACC était près de deux fois plus élevé que celui déclaré par les autres USIN canadiennes.

OBJECTIF : Adopter une collaboration visant l'amélioration de la qualité pour réduire l'incidence d'ISACC néonatales.

MÉTHODOLOGIE : La présente étude rétrospective d'observation visait à comparer les ISACC chez les nouveau-nés admis à l'USIN de niveau III des auteurs entre août 2007 et mars 2011. Les auteurs ont divisé l'étude en quatre périodes pour évaluer les tendances séculaires. Une initiative complète de prévention des infections sanguines associées au cathéter a été adoptée en août 2007. Elle incluait la formation du personnel, la standardisation du protocole de préparation de la peau, l'introduction de nouveaux antiseptiques, l'adoption d'aide-mémoire sur l'insertion et l'entretien du cathéter central, le renforcement des précautions maximales entourant la barrière stérile et la révision des protocoles de configuration et d'entretien du cathéter central.

RÉSULTATS : Le taux médian d'ISACC de 7,9 sur 1000 jourscathéter en début d'étude (période 1 [août 2007 à juin 2008]) a fléchi graduellement jusqu'à la fin de l'étude $(\mathrm{P}=0,034)$ : période 2 (juillet 2008 à mai 2009), 3,3 sur 1000 jours-cathéter; période 3 (juin 2009 à avril 2010), 2,6 sur 1000 jours-cathéter; et période 4 (mai 2010 à mars 2011), 2,2 sur 1000 jours-cathéter.

CONCLUSION : Une collaboration multidisciplinaire visant l'amélioration de la qualité fondée sur des données probantes a réduit considérablement les ISACC. Des mesures continues d'amélioration de la qualité s'imposent pour réduire les infections sanguines associées au cathéter chez les nourrissons de petit poids à la naissance.

two years of age $(2,4)$. Several studies have reported experiences in implementing evidence-based central line bundles to reduce CLABSI rates in the intensive care settings $(1,3,5-7)$. An updated guideline for the prevention of intravascular catheter-related infections was published by the Centers for Disease Control and Prevention (Georgia, USA) in 2011 (8).

In 2006/2007, the CLABSI rate of 11.8 per 1000 central catheter days in the neonatal intensive care unit (NICU) at BC Women's 
Hospital \& Health Centre (Vancouver, British Columbia) was higher than that reported by other Canadian NICUs (9). The central line insertion practices were thoroughly revised and a quality improvement collaborative was implemented. The initial objective of the present quality assurance project was to reduce line-related sepsis according to the Centers for Disease Control and Prevention CLABSI definition (before 2008) in NICUs by 50\% within a period of one year (10).

The present retrospective study sought to determine whether the implementation of a pre- and postinsertion care bundle reduced the CLABSI rate. We hypothesized that, following the systemic intervention, which included staff education, implementation of evidencebased bundles for central-line insertion, access and maintenance, and timely feedback on CLABSI occurrence, a significant reduction in CLABSI would be achieved.

\section{Study population and setting}

\section{METHODS}

The present study was conducted at the NICU at BC Women's Hospital \& Health Centre, a quaternary care institution in Western Canada. The NICU contains 60 beds and serves a population of four million inhabitants of both British Columbia and the Yukon Territory. CLABSI rates in neonates admitted from August 2007 to March 2011, inclusive, were compared. The entire study period was divided into four periods to evaluate the secular trends.

\section{Definition of CLABSI}

CLABSI was defined using the Canadian Nosocomial Infection Surveillance Program or National Healthcare Safety Network definition $(11,12)$. A CLABSI was defined as the following:

- recovery of a recognized pathogen from one or more blood cultures, and the organism cultured from blood not related to an infection at another site; or

- the presence of at least one of the following:

- fever (core temperature $>38^{\circ} \mathrm{C}$ ), hypothermia (core temperature $<36^{\circ} \mathrm{C}$ ), apnea or bradycardia;

- signs, symptoms and positive laboratory results not related to an infection at another site;

- common skin commensal bacteria (ie, diphtheroids, Bacillus species, Propionibacterium species, coagulase-negative staphylococci, viridans group streptococci, Micrococcus species) recovered from $\geq 1$ blood culture; and

- appropriate antimicrobial therapy instituted by physician.

The presence of a central line was required at the time of infection or within the $48 \mathrm{~h}$ period before the development of the infection. Central lines used in the authors' NICU include: umbilical catheters, peripherally inserted central catheters (PICCs) and, infrequently, cuffed and short-term noncuffed catheters.

\section{Assessing the problem and design of interventions}

A prospective six-month cohort with a nested case-control study was conducted by the Public Health Agency of Canada to determine the rate of and risk factors associated with CLABSIs in Canadian intensive care units. The CLABSI rate of 11.8 per 1000 central catheter days in the authors' NICU was higher than the national rate of 6.8 per 1000 catheter days (9). A 'No-Bugs Project' committee, aiming at reducing the CLABSI rate, was assembled in the hospital in June 2007. Members included representatives from the health care team with expertise in different aspects of CVC-related practice (ie, neonatal physicians and nurses, practitioners from the hospital Infection Control Department [ICD] and the program Quality and Safety Committee). A nurse educator was appointed to coordinate surveillance and practice changes. The ICD of the hospital conducted regular surveillance of CLABSI and summarized the results on a monthly basis. The number of positive blood cultures per 1000 catheter days and line utilization rates were determined. Medical literature was identified, reviewed and disseminated to the committee. The literature was assessed for methodological quality and applicability to the authors' unit. A comprehensive catheterrelated BSI prevention initiative was then developed. The bundle of measures, implemented in a stepwise manner beginning in August 2007, included staff education, standardization of the skin preparation protocol, introduction of new antiseptic agents, implementation of central catheter insertion and maintenance checklists, reinforcement of the use of maximal sterile barrier precautions, and revision of central venous line configuration and maintenance. The entire scheme was implemented through 10 Plan-Do-Study-Act (PDSA) cycles.

\section{PDSA cycles}

Cycle 1 - Surveillance of current practices: An observational survey of catheter insertion and maintenance was performed to understand the existing practices and identify problems (Appendixes $1 \mathrm{~A}$ and $1 \mathrm{~B}$ ). Surveys of compliance with the use of proper hand-washing technique, antiseptic soap, maximal barrier (long-sleeved, sterile surgical gown, sterile gloves, mask and large sterile drape), skin antisepsis and maintenance of aseptic technique during catheter insertion were conducted. The following parameters were also recorded: the method of securing the catheter (suture versus tape) before radiographic confirmation of line position; compliance with aseptic technique when attaching fluid or infusion lines to the catheter hub; the unnecessary addition of ports to the infusion system; the application of transparent dressing in an aseptic manner; and whether the cleaning, insertion and connection of intravenous tubings were performed in accordance with existing standards of practice.

Cycle 2 - Enhancement of awareness among NICU staff: Posters, e-mail notices, and one-on-one and small-group information sessions were used to enhance the awareness of CLABSI rates in the unit. The No Bugs Project committee members met weekly to address current issues, to answer questions from staff and to enhance two-way communication.

Cycle 3 - Revision of skin preparation protocol: The skin preparation protocol was standardized per recommendations from the ICD: a solution of $2 \%$ chlorhexidine with $4 \%$ isopropyl alcohol (Dexidin, Laboratoire Atlas Inc, Canada) to be applied to the skin around the insertion site, left for $30 \mathrm{~s}$ and allowed to air dry for an additional $60 \mathrm{~s}$, in accordance with published recommendations $(13,14)$. Infants weighing $<1000 \mathrm{~g}$ also had normal saline applied for skin cleansing after application of Dexidin to prevent skin injury caused by the antiseptic solution (15).

Cycle 4 - Practice change for cleaning intravenous tubings, ports and medication vials: For central-line dressing changes (eg, tubing, ports, medication vials) and skin antisepsis for heel lancing, 70\% isopropyl alcohol swabs were replaced with swabs impregnated with $2 \%$ chlorhexidine gluconate and 70\% isopropyl alcohol (16).

Cycle 5 - Checklist for central-line insertion: To improve the awareness of infection control and to reduce central-line infections, a central-line insertion checklist was created. Both small-group and one-on-one teaching sessions were used to implement the checklist. An audit was to be completed by the bedside nurse at each insertion to document adherence to the central-line insertion bundle (Appendix 2).

Cycle 6 - Central-line insertion cart checklist: The central-line cart contains 'adequate' but 'not excessive' supplies essential for the operator to comply with the best infection control practices. A checklist was created after repeated consultations with the staff (Appendix 3). The central catheter and umbilical line carts were reviewed and revised.

Cycle 7 - Enhancement of maximal barrier precaution (mask): Boxes of appropriate surgical masks were made readily available at the unit sites for central catheter insertion.

Cycle 8 - Trial of surgical disposable scalpel: Surgical disposable blades were introduced to reduce the risk of injury.

Cycle 9 - Central venous line configuration and maintenance: Surveillance and education sessions were introduced to ensure $100 \%$ 
TABLE 1

Catheter use and characteristics of central line-associated bloodstream infections (CLABSI) across the study period

\begin{tabular}{|c|c|c|c|c|c|}
\hline \multirow[b]{2}{*}{ Characteristic } & \multicolumn{4}{|c|}{ Period $^{*}$} & \multirow[b]{2}{*}{$\mathbf{P}$} \\
\hline & 1 & 2 & 3 & 4 & \\
\hline Total catheter days & 3958 & 4004 & 4527 & 4068 & 0.580 \\
\hline Median number of CLABSIs per 1000 catheter days & 7.9 & 3.3 & 2.6 & 2.2 & 0.034 \\
\hline Median birth weight, g & 1561 & 809 & 686 & 950 & 0.008 \\
\hline Median time to onset of infections after line insertion, days & 15 & 8 & 7 & 14 & 0.006 \\
\hline
\end{tabular}

${ }^{*}$ Period 1, August 2007 to June 2008; period 2, July 2008 to May 2009; period 3, June 2009 to April 2010; period 4, May 2010 to March 2011

compliance with the standard line configuration and line maintenance schedule including: change of smart site cap every six days, when dislodged or when visibly contaminated in cases of suspected catheterrelated sepsis; and change of T-connector every $72 \mathrm{~h}$, when dislodged, when visibly contaminated or within $24 \mathrm{~h}$ of blood product transfusion.

Cycle 10 - Hand hygiene: Hand washing is the most important procedure to prevent the spread of infection $(17,18)$. Notices were posted at the entrance of the NICU to remind all visitors of the importance of the initial scrub for the day (removal of rings, bracelets and watch, keeping sleeves above elbows, and application of chlorhexidine gluconate $2 \%$ to thoroughly wash hands and arms). Neutral soap, antimicrobial soaps (chlorhexidine gluconate) and alcohol-based hand scrubs were made readily available in the unit. Hand-hygiene surveillance was not only targeted toward physicians and nurses, but also toward other health care providers such as physiotherapists, radiology technicians and ward clerks. Regular teaching and audit sessions were conducted to enhance the practice. Compliance with hand hygiene was announced regularly (eg, on notice boards) to enhance the awareness among staff.

PDSA cycles 1 to 9 were implemented over a seven-month period. Hand hygiene surveillance and auditing were conducted on an ongoing basis.

\section{Statistical analysis}

SPSS version 19.0 (IBM Corporation, USA) was used for statistical analysis. A Kruskal-Wallis one-way ANOVA was used to compare the medians of birth weight, gestational age and the onset of infection in each of the four time periods, and the CLABSI rates across the entire study period. ANOVA was used to compare the total catheter days in each period. Linear regression was used to demonstrate the trend of change in infection per 1000 catheter days over the study period.

\section{RESULTS}

During the entire study period, there was no major change in the practice of central catheter insertion and removal, and the total catheter days remained steady at approximately 4000 to 4500 days per period $(\mathrm{P}=0.580)$.

In the observational survey for catheter insertion and maintenance in PDSA cycle 1, proper hand washing, the use of maximal barrier and maintenance of aseptic technique were found to be achieved in all cases. However, in more than one-half of cases, inadequate time was permitted for both cleaning and drying after the application of chlorhexidine to the skin.

Monthly CLABSI rates decreased over the course of the study (Figure 1). The median CLABSI rate of 7.9 per 1000 catheter days at the beginning of the study (period 1; August 2007 to June 2008) gradually decreased over the entire study period $(\mathrm{P}=0.034)$ : period 2 (July 2008 to May 2009), 3.3 per 1000 catheter days; period 3 (June 2009 to April 2010), 2.6 per 1000 catheter days; and period 4 (May 2010 to March 2011), 2.2 per 1000 catheter days (Table 1).

\section{DISCUSSION}

CLABSI is a clinical definition used when diagnosing and treating patients with the support of specific laboratory testing. It is often

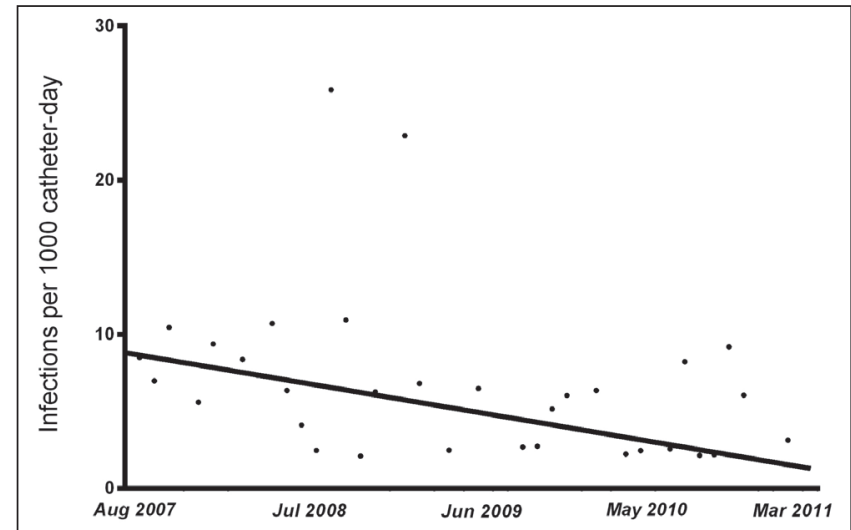

Figure 1) Monthly central line-associated bloodstream infection rates across the study period. Aug August; Jul July; Jun June; Mar March

difficult, if not extremely challenging, to precisely establish whether a BSI is catheter related because of the limited availability and difficulties in implementing microbiological methods in the neonatal setting (8).

Our findings demonstrate a significant reduction in CLABSI rate, decreasing from 7.9 per 1000 catheter days in late 2007 to 2.2 per 1000 catheter days in early 2011 after implementation of a central catheter care bundle despite no major changes in central catheter use. Although the approaches to individual aspects of central-catheter management may be efficacious, the greatest success has been reported with the use of the catheter care bundle (7). The strength of the project is that, with the application of PDSA cycles developed by a multidisciplinary task force, and implementation of bundles using small-group and one-on-one teaching sessions, a highly desirable result can be achieved.

Different studies have shown that surveillance of existing data, conducting education sessions and periodic assessment of knowledge and adherence to guidelines for all personnel involved in the insertion and maintenance of central catheters are essential to an effective prevention program targeted at the elimination of CLABSIs (19-22). In our bundle, we emphasized the basic NICU precautions, including proper hand hygiene, aseptic technique and the use of maximal sterile barrier precautions, that the literature has shown to be the essential elements in reducing CLABSIs (23-25). The chlorhexidine gluconate/alcohol preparation that we chose as a skin antisepsic has also been shown to result in lower rates of catheter colonization or CLABSI, and has been found to be cost effective (26-28). We adopted the policy of immediately wiping away the excess chlorhexidine with normal saline to minimize the exposure of delicate and immature skin of extreme premature infants ( $\leq 28$ weeks' gestation) to the antiseptic solution to avoid chemical burns (29). Iodine-containing products were avoided because of the potential adverse effects on the neonatal thyroid (30). The postinsertion care bundle may also have played an important role in the reduction of CLABSIs. We standardized and reinforced the application of antiseptic swabs impregnated with 2\% chlorhexidine gluconate and 70\% isopropyl alcohol to decontaminate the injection port or central catheter hub before and after accessing the system (6,31-33). 
PDSA cycles have been promoted as effective tools for managing practice adoption and establishing habits for improving practice standards (34-36). Timely audits and feedback are essential to define objectives and measure progress (37), and we believe that our smallgroup and one-on-one teaching sessions are valuable tools to achieve this and to ensure good outcomes. Such close interactions between our team and the other NICU staff enabled us to establish trust and improve the newly implemented practices in a timely manner.

We found that the median weight and gestational age of neonates with CLABSI decreased over time. This finding is most likely explained by the fact that those belonging to the extremely premature ( $\leq 28$ weeks) or extremely low-birth-weight ( $\leq 1000 \mathrm{~g}$ ) groups were most vulnerable to infections due to their immature skin, immunocompromised state and the need for a longer period of parenteral nutrition.

\section{CONCLUSION}

A multidisciplinary evidence-based quality improvement collaborative resulted in a significant reduction in CLABSI rate. Continuous quality improvement measures are needed in reducing catheter-related BSIs among extremely low-birth-weight infants.

ACKNOWLEDGEMENTS: The authors thank Dr John Smyth, Dr Susan Albershiem, Dr Rita Nathawad and Valoria Halt for their valuable comments and editorial assistance. The authors also thank Ruth Milner for her advice regarding statistical analysis. The authors are grateful to members of the No-Bugs Project committee for the design and implementation of the bundles described.

DISCLOSURES: The authors have no conflicts of interest to declare. Financial support: None.

\section{APPENDIX 1A}

Observational survey "How central lines are being inserted in our NICU"

$\begin{array}{ll}\text { Items } & \text { Yes No }\end{array}$

1. Proper hand washing with antiseptic soap prior to procedure.

2. Are maximal barriers being used?

Maximal barriers $=$ long-sleeved sterile surgical gown, sterile gloves, mask, and large sterile drape

3. Is chlorhexidine $2 \%$ being used for cleaning?

4. Is the line insterted aseptically?

5. Is there a break in sterility by the assistant?

6. Is there any break in sterility during/throughout the insertion?

7. Is the line(s) sutured/taped before $x$-ray?

8. Is there a break in sterility while waiting for $\mathrm{x}$-ray?

9. Are fluids/tubings being attached to hub aseptically?

10. Did the person (usually the nurse) attaching the fluids wash his/her hands before doing so?

11. Are there any unnecessary ports/pig tails added?

12. Is there a port designated for TPN?

13. Is the line dressed with transparent dressing aseptically?

14. Are policies and procedures being followed for cleaning, insertion and attaching IV tubings?

15. Is this an experienced physician/certified PICC nurse inserting the line?

16. Did the assistant maintain the sterility of the surrounding area during insertion?

IV Intravenous; NICU Neonatal intensive care unit; PICC Peripherally inserted central catheter; TPN Total parenteral nutrition
APPENDIX 1B

Observational Survey "How central lines are being treated/ maintained in our NICU"

\begin{tabular}{ll}
\hline Items & Yes No \\
\hline
\end{tabular}

1. Wash hands prior to touching the line (for hands on assessment)

2. Assess system: ?Closed system; all connections are tight and secure?

3. Assess CVL dressing via palpation.

4. Is line being accessed aseptically via med port?

a. Swab med port on $\mathrm{T}$ piece prior to accessing line

b. Scrubbing up and down on the IV tubing and line?

c. How long is med port scrubbed for?

d. Does the nurse wait for the port to dry after swabbing before accessing?

5. Is there a break in the sterility during TPN change?

6. Is the line being accessed aseptically during daily TPN change?

7. Are IV antibiotics being given via the CVL if in place?

8. Is PIV being started for antibiotic administration?

9. Does the nurse touch the line/parts of it during hourly assessment?

10. Is the line being placed away from potential areas of contamination, e.g., ostomy bag \& diaper?

11. Is there a smart cap at the hub of the line?

12. Is there an expiry date on bag/tubing/transducer/hub?

13. Are the unnecessary ports/pig tails removed?

14. Is the CVL dressing changed routinely, i.e. at 7 days and then prn?

15. Is the CVL permanent cap changed routinely?

16. Does the nurse touch the line after touching other "dirty" items of after performing a "dirty" task, e.g. Changing diaper?

17. Does the nurse wash hands after she completes her assessment/handling?

18. Is the nurse following all the relevant polocies and procedures? E.g., follow dressing change P\&P when performing dressing change.

19. Is this a new nurse or an experienced nurse?

20. Does the nurse educate the families about the line? E.g., teach parents re: potential of contamination during diaper change/cuddling, tubing touching the floor etc.

21. Is there a tracking sheet for the line by the bedside?

22. Does the nurse/physician review the need for line on a daily basis?

CVL Central venous line; IV Intravenous; P\&P Policy and procedure; TPN Total parenteral nutrition

\section{APPENDIX 2}

\section{NICU Central Line Insertion Procedure Checklist}

\section{Purpose}

- Teamwork to decrease risk from central catheter-related-bloodstream infection.

- To audit adherence to central line insertion bundle per CDC guidelines.

- To be filled out by bedside nurse or assistant for ALL central insertions in NICU EXCEPT during emergency situation

Procedure: Umbilical PICC CVC

Before the Procedure

\section{Assistant}

Wash hands

Assemble equipment/verify supplies 


\section{APPENDIX 2}

\section{NICU Central Line Insertion Procedure Checklist - CONTINUED}

Inform Radiology (on nights/as needed)

Get a screen to enclose the area for insertion procedure

Post sign to indicate "STERILE PROCEDURE IN PROGRESS"

Procedure MD/PCRN

Yes No Reminder

Assess, cleanse (PRN) and mark site

Position patient correctly for procedure

Wear mask and hat

Wash hands (ASK if unsure)

Wear sterile gown and gloves

Drape a large area exposing ONLY site

Prepare site with $2 \%$ chlorhexidine $/ 4 \%$ alcohol solution

Prepare site for 30 seconds

Dry for up to 60 seconds without fanning/wiping

Maintain sterile field throughout procedure

Did the assisting MD/PCRN follow the same

precautions? (Hand washing, mask, gloves and

gown)

Was chlorhexidine residual removed for infant

$<1000$ gm?

Was sterility maintained when applying dressing/

stitches?

Was sterile field compromised during line

readjustment?

Were IV fluids/lines being attached aseptically?

Was the procedure documented in the NICU CVL

Registry?

Date of procedure:

Name of procedure MD/PCRN:

Name of assistant:

Name of auditor (if different from assistant):

PLEASE RETURN COMPLETED INSERTION CHECKLIST AND REGISTRY TO NICU CENTRAL LINE REGISTRY BINDER IN THE CNL OFFICE

CDC Centers for Disease Control and Prevention (Georgia, USA); CNL Clinincal nurse leader; CVC Central venous catheter; CVC Central venous line; MD Medical doctor; NICU Neonatal intensive care unit; PCRN Peripherally inserted central catheter-certified registered nurse; PRN Pro re nata (as needed)

\section{APPENDIX 3}

\section{Central Line Insertion Cart}

\section{Top Shelf}

\begin{tabular}{ll}
\hline Sterile Towels & 8 \\
Sterile Gowns & 4 \\
Caps (in plastic bag) & 4 \\
Masks (Blue Surgical and Yellow Procedure) & 1 box each \\
Bottom Shelf & \\
\hline Cutdown trays & 2 \\
UAC Trays & 2 \\
\#4 Fr. Double Lumen CVC Kits & 2 \\
\#3 Fr. Single Lumen CVC Kit(s) & 1 \\
\#2.5 Fr. Cook Single Lumen CVC Kit(s) & 1 \\
\#2 Fr. Per-Q-Cath Trays & 4 \\
\#1 Fr. Premicath & 4 \\
Spring wire 0.18" (0.46mm ) diameter & 2 \\
Drawer & \\
\hline Sterile Gloves & 4 each of size 6, \\
1\% Xylocaine & $6.5,7,7.5,8$ \\
Measuring Tape & 4 \\
0.9\% NaCl Vial & 4 \\
0.9\% NaCl AddiPaks for rinsing & 4 \\
$0.9 \%$ NaCl Pre-filled Syringe Package & 4 \\
\end{tabular}

\section{APPENDIX 3}

\section{Central Line Insertion Cart}

\begin{tabular}{ll}
\hline 5mL Syringe & 4 \\
10mL Syringe & 4 \\
Needles (22G, 27G) & 4 each \\
Catheter Introducer (22G, 24G) & 4 each \\
4 "x4" Gauze & 4 \\
2"x2" Gauze & 1 box \\
Steri-stripes & 8 \\
\#3.0 Silk Suture & 4 \\
Sterile Scissors & 2 \\
Sterile Scissors and Tweezers set & 2 \\
Penrose Tubing & 2 each of small and \\
& large \\
Dexidin 2 Solution (2\% Chlorhaxidine with 4\% alcohol) & 4 \\
IV Extension Set & 4 \\
Spring Wire Guide & 4 \\
Thrombostat Dressing Pack & 4 \\
Tegaderm small (4.4cm x 4.4cm) & 4 \\
Tegaderm medium (6cm x 7cm) & 4 \\
Tegaderm large (10cm x 12cm) & 4 \\
Clamps, non-tooth, non-sterile & 4 \\
Alcohol for cleaning cart top & 4 \\
Tapes & 4 \\
\hline
\end{tabular}

Tapes

Tegaderm manufactured by $3 \mathrm{M}$ Health Care (USA). CVC Central venous catheter; IV Intravenous; UAC Umbilical artery catheter

\section{REFERENCES}

1. Wirtschafter DD, Pettit J, Kurtin P, et al. A statewide quality improvement collaborative to reduce neonatal central lineassociated blood stream infections. J Perinatol 2010;30:170-81.

2. Stoll BJ, Hansen N, Fanaroff AA, et al. Late-onset sepsis in very low birth weight neonates: The experience of the NICHD Neonatal Research Network. Pediatrics 2002;110:285-91.

3. Powers RJ, Wirtschafter DW. Decreasing central line associated bloodstream infection in neonatal intensive care. Clin Perinatol 2010;37:247-72.

4. Shah DK, Doyle LW, Anderson PJ, et al. Adverse neurodevelopment in preterm infants with postnatal sepsis or necrotizing enterocolitis is mediated by white matter abnormalities on magnetic resonance imaging at term. J Pediatr 2008;153:170-5.

5. Costello JM, Morrow DF, Graham DA, Potter-Bynoe G, Sandora TJ, Laussen PC. Systematic intervention to reduce central line-associated bloodstream infection rates in a pediatric cardiac intensive care unit. Pediatrics 2008;121:915-23.

6. Guerin K, Wagner J, Rains K, Bessesen M. Reduction in central line-associated bloodstream infections by implementation of a postinsertion care bundle. Am J Infect Control 2010;38:430-3.

7. Li S, Bizzarro MJ. Prevention of central line associated bloodstream infections in critical care units. Curr Opin Pediatr 2011;23:85-90.

8. O'Grady NP, Alexander M, Burns LA, et al. Guidelines for the prevention of intravascular catheter-related infections. Clin Infect Dis 2011;52:e162-93.

9. Holton D, Paton S, Conly J, Embree J, Taylor G, Thompson W. Central venous catheter-associated bloodstream infections occurring in Canadian intensive care units: A six-month cohort study. Can J Infect Dis Med Microbiol 2006;17:169-76.

10. Horan TC, Andrus M, Dudeck MA. CDC/NHSN surveillance definition of health care-associated infection and criteria for specific types of infections in the acute care setting. Am J Infect Control 2008;36:309-32.

11. Central Venous Catheter-Associated Blood Stream Infections In Intensive Care Units. The Canadian Nosocomial Infection Surveillance Program; 2010.

12. O'Grady NP, Alexander M, Dellinger EP, et al. Guidelines for the prevention of intravascular catheter-related infections. Centers for Disease Control and Prevention. MMWR Recomm Rep 2002;51:1-29.

13. Hibbard JS, Mulberry GK, Brady AR. A clinical study comparing the skin antisepsis and safety of ChloraPrep, 70\% isopropyl alcohol, and 2\% aqueous chlorhexidine. J Infus Nurs 2002;25:244-9. 
14. Malathi I, Millar MR, Leeming JP, Hedges A, Marlow N. Skin disinfection in preterm infants. Arch Dis Child 1993;69(3 Spec No):312-6.

15. Reynolds PR, Banerjee S, Meek JH. Alcohol burns in extremely low birthweight infants: Still occurring. Arch Dis Child Fetal Neonatal Ed 2005;90:F10.

16. Adams D, Quayum M, Worthington T, Lambert P, Elliott T. Evaluation of a $2 \%$ chlorhexidine gluconate in $70 \%$ isopropyl alcohol skin disinfectant. J Hosp Infect 2005;61:287-90.

17. Fryklund B, Tullus K, Berglund B, Burman LG. Importance of the environment and the faecal flora of infants, nursing staff and parents as sources of Gram-negative bacteria colonizing newborns in three neonatal wards. Infection 1992;20:253-7.

18. Graham PL 3rd. Simple strategies to reduce healthcare associated infections in the neonatal intensive care unit: Line, tube, and hand hygiene. Clin Perinatol 2010;37:645-53.

19. Semelsberger CF. Educational interventions to reduce the rate of central catheter-related bloodstream infections in the NICU: A review of the research literature. Neonatal Netw 2009;28:391-5.

20. Coopersmith CM, Rebmann TL, Zack JE, et al. Effect of an education program on decreasing catheter-related bloodstream infections in the surgical intensive care unit. Crit Care Med 2002;30:59-64.

21. Warren DK, Zack JE, Mayfield JL, et al. The effect of an education program on the incidence of central venous catheter-associated bloodstream infection in a medical ICU. Chest 2004;126:1612-8.

22. Yoo S, Ha M, Choi D, Pai H. Effectiveness of surveillance of central catheter-related bloodstream infection in an ICU in Korea. Infect Control Hosp Epidemiol 2001;22:433-6.

23. Raad, II, Hohn DC, Gilbreath BJ, et al. Prevention of central venous catheter-related infections by using maximal sterile barrier precautions during insertion. Infect Control Hosp Epidemiol 1994;15(4 Pt 1):231-8.

24. Abi-Said D, Raad I, Umphrey J, et al. Infusion therapy team and dressing changes of central venous catheters. Infect Control Hosp Epidemiol 1999;20:101-5.

25. Pittet D, Dharan S, Touveneau S, Sauvan V, Perneger TV. Bacterial contamination of the hands of hospital staff during routine patient care. Arch Intern Med 1999;159:821-6.

26. Maki DG, Ringer M, Alvarado CJ. Prospective randomised trial of povidone-iodine, alcohol, and chlorhexidine for prevention of infection associated with central venous and arterial catheters. Lancet 1991;338:339-43.

27. Mimoz O, Pieroni L, Lawrence C, et al. Prospective, randomized trial of two antiseptic solutions for prevention of central venous or arterial catheter colonization and infection in intensive care unit patients. Crit Care Med 1996;24:1818-23.

28. Chaiyakunapruk N, Veenstra DL, Lipsky BA, Saint S. Chlorhexidine compared with povidone-iodine solution for vascular catheter-site care: A meta-analysis. Ann Intern Med 2002;136:792-801.

29. Lashkari HP, Chow P, Godambe S. Aqueous $2 \%$ chlorhexidineinduced chemical burns in an extremely premature infant. Arch Dis Child Fetal Neonatal Ed 2012;97:F64.

30. O'Grady NP, Alexander M, Burns LA, et al. Guidelines for the prevention of intravascular catheter-related infections. Am J Infect Control 2011;39(4 Suppl 1):S1-34 .

31. Soothill JS, Bravery K, Ho A, Macqueen S, Collins J, Lock P. A fall in bloodstream infections followed a change to $2 \%$ chlorhexidine in $70 \%$ isopropanol for catheter connection antisepsis: A pediatric single center before/after study on a hemopoietic stem cell transplant ward. Am J Infect Control 2009;37:626-30.

32. McDonald LC, Banerjee SN, Jarvis WR. Line-associated bloodstream infections in pediatric intensive-care-unit patients associated with a needleless device and intermittent intravenous therapy. Infect Control Hosp Epidemiol 1998;19:772-7.

33. Pratt RJ, O'Malley B. Supporting evidence-based infection prevention and control practice in the National Health Service in England. The NHS/TVU/Intuition Approach. J Hosp Infect 2007;65(Suppl 2):142-7.

34. Horbar JD, Plsek PE, Leahy K. NIC/Q 2000: Establishing habits for improvement in neonatal intensive care units. Pediatrics 2003;111(4 Pt 2):e397-410.

35. Lee SK, Aziz K, Singhal N, et al. Improving the quality of care for infants: A cluster randomized controlled trial. CMAJ 2009;181:469-76.

36. Kilbride HW, Wirtschafter DD, Powers RJ, Sheehan MB. Implementation of evidence-based potentially better practices to decrease nosocomial infections. Pediatrics 2003;111(4 Pt 2):e519-33.

37. Randolph G, Esporas M, Provost L, Massie S, Bundy DG. Model for improvement - part two: Measurement and feedback for quality improvement efforts. Pediatr Clin North Am 2009;56:779-98. 


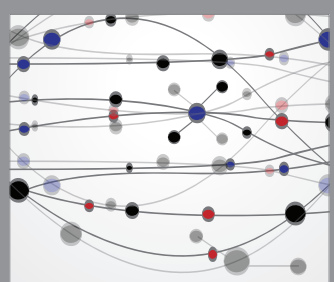

The Scientific World Journal
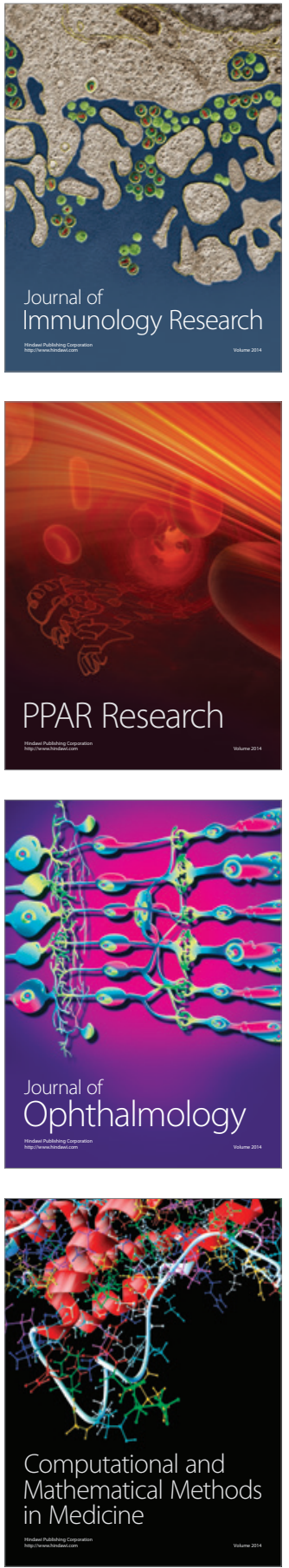

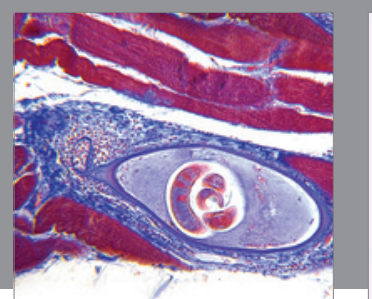

Gastroenterology Research and Practice

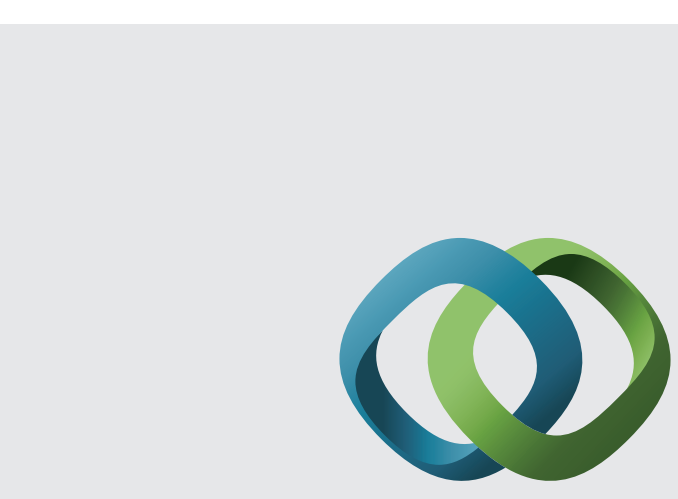

\section{Hindawi}

Submit your manuscripts at

http://www.hindawi.com
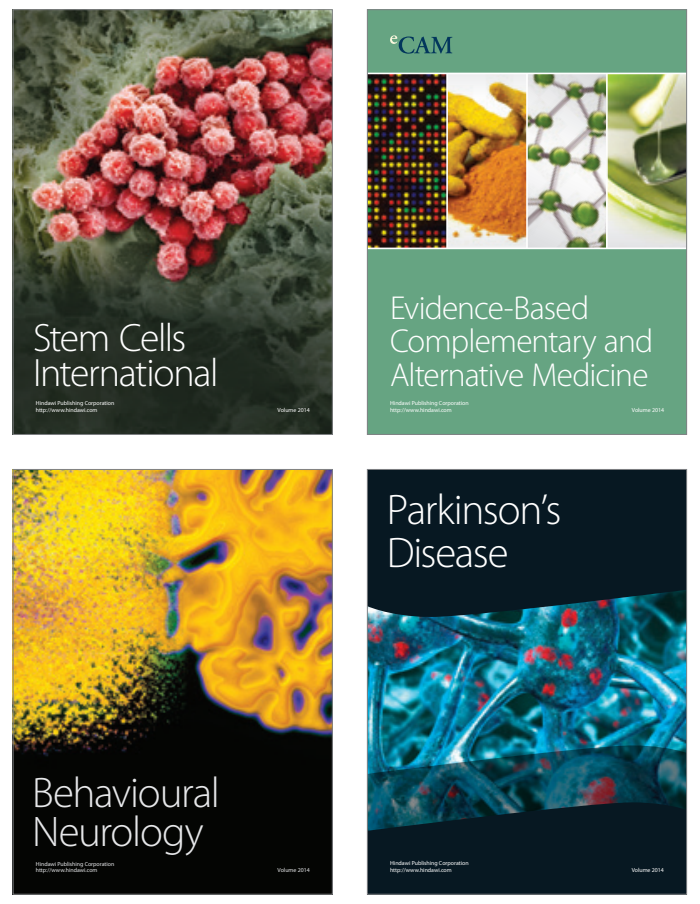
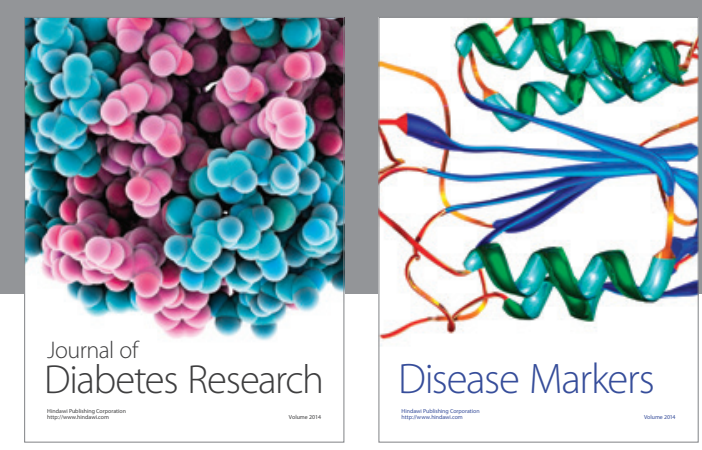

Disease Markers
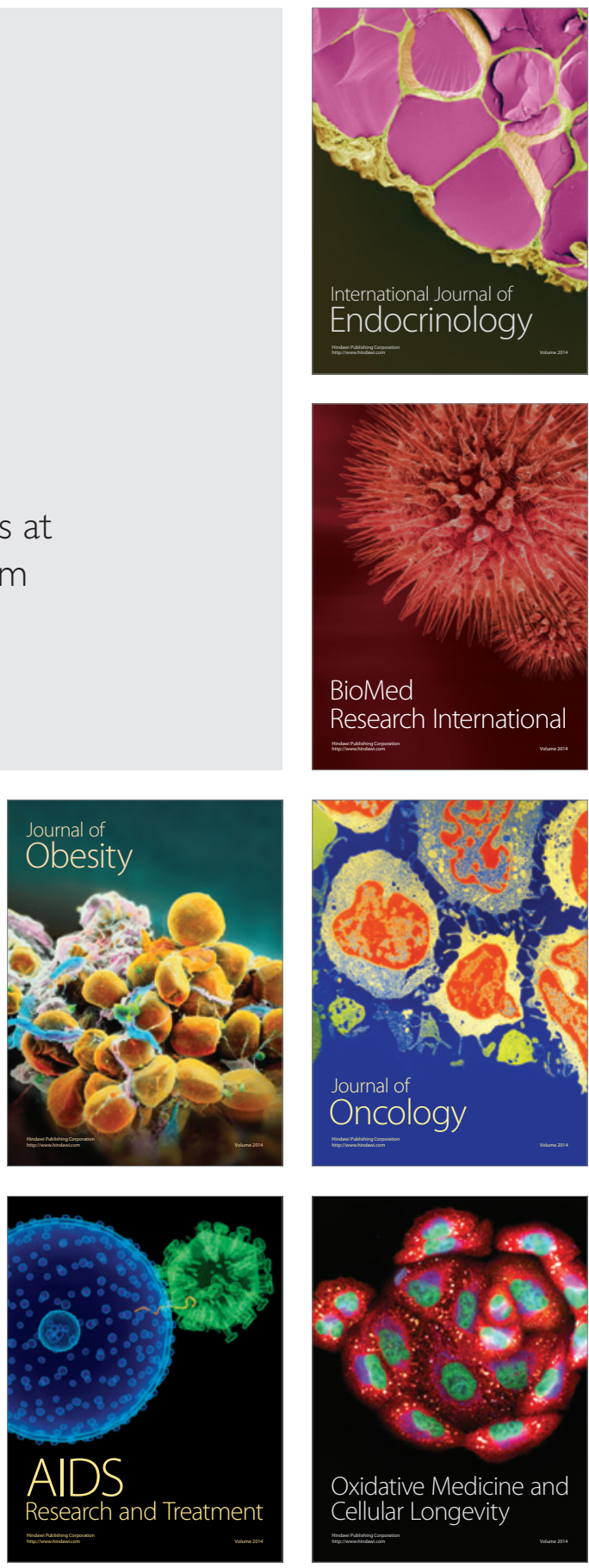